\title{
Contrasting Instructional Technology Adoption in K-12 Education to Promote Digital Equity
}

\author{
Erik Kormos, Ashland University, USA
}

Liliana Julio, Universidad Simon Bolivar, Colombia

\begin{abstract}
This quantitative study examined the frequency of usage and teacher perception of educational technology by $\mathrm{K}-12$ public school teachers in three geographic settings: urban, rural, and suburban. The objective aimed to uncover any significant relationship between variables in an effort to better understand trends in the professional environment. A survey of 2,200 educators in a Mid-Atlantic state revealed significant differences of perception and usage. The inquiry discovered teachers from urban schools trailed suburban and rural schools in nearly all objectives. Suburban schools reported the highest perception levels of technology effectiveness, trailed consistently by their rural peers. Current teachers, administrators, and teacher educators may utilize this research to personalize technologies for their student population and develop strategies to increase teacher perception of technology, particularly in the urban setting.
\end{abstract}

\section{KEYWORDS}

Frequency of Usage, Rural Schools, School Setting, Suburban Schools, Teacher Attitudes, Teacher Perceptions, Urban Schools

\section{INTRODUCTION}

Educational technologies play an essential part in the learning process and provide teachers an ability to develop multiple 21st-century skills of their students. Higher rates of technology usage in K-12 classrooms has been linked to elevated levels of critical thinking, problem solving, and communication skills (Chai \& Kong, 2017). The Association for Educational Communications and Technology (AECT) define educational technology as "the study and ethical practice of learning and improving performance by creating, using, and managing appropriate technological processes and resources" (Januszewski \& Molenda, 2013). Educational technologies may provide another mechanism to overcome obstacles encountered during instruction such as outdated content, damaged resources, lack of opportunities for writing and communication, and accessibility. Educational technology enables teachers to create a student-centered classroom and deviate from conventional methods of delivery such as worksheets and lecture (Spencer, 2017).

This article, originally published under IGI Global's copyright on July 1, 2020 will proceed with publication as an Open Access article starting on January 28, 2021 in the gold Open Access journal, International Journal of Web-Based Learning and Teaching Technologies (converted to gold Open Access January 1, 2021), and will be distributed under the terms of the Creative Commons Attribution License (http:// creativecommons.org/licenses/by/4.0/) which permits unrestricted use, distribution, and production in any medium, provided the author of the original work and original publication source are properly credited. 
This quantitative investigation sought to better understand teacher usage frequencies and attitude toward educational technology by geographic setting. Results from this researcher-designed survey may assist teachers and administrators identify strategies to enhance teacher attitude and designate specific needs of improvement. In addition, this data provides a template for technology usage in an effort to meet the differences and diverse needs that are present in each learning community. For the purpose of this study, usage is defined as "the frequency in which a teacher implements a specific online-based educational technology into curriculum design and implementation inside and outside of the physical classroom." Attitude is operationally defined as "the way in which a teacher regards, understands, and interprets the effectiveness of educational technology within the framework of teaching and learning."

\section{LITERATURE REVIEW}

\section{American K-12 Education and Technology}

Educational technology has become a staple of day-to-day operations in all levels of education, including K-12 public schools. Over the past 25 years, teacher and student access to educational technologies has increased at a rapid pace. In 1994, only one computer was available for every 20 students. In 2016, that ratio has dropped to one computer for every two students in U.S. public schools (Herold, 2016). Now many schools allocate tablets for kindergarten students and offer a wide variety of virtual online secondary school courses. As student access to computers increased, so did finances dedicated to technology. In 2015, American K-12 schools spent \$8.3 billion dollars on technology, with $\$ 3$ billion used on digital content alone. These figures are a $12 \%$ increase from 2014 and projected to expand each of the next five years (Chen, 2015). Overall spending on educational technology has surpassed $\$ 630$ billion, roughly $\$ 12,608$ per student (Herold, 2016). The United States Department of Education has recognized the importance of educational technology within public schools. The department declared "technology is at the core of virtually every aspect of our daily lives in work, and we must leverage it to provide engaging and powerful learning experiences and content" (U.S. Department of Education, 2010). Gradelevel technology standards have been adapted at the local level as well, with each state having incorporated technology benchmarks into their curriculum. For the purpose of this research, technology hardware, or the physical parts of a computer such as the monitor, keyboard, and mouse were not examined. Technology software such as word processing programs, Internet browsers, and operating systems were also excluded. Rather, the research focused on onlinebased educational technology designed to enrich the learning process.

\section{Public Schools and Technology}

This Mid-Atlantic state is comprised of 501 public school districts that operate 3,068 schools, not including an additional 176 charter schools. The state is home to 260 rural, 209 suburban and 32 urban districts (National Center for Education Statistics, 2015). In 2015, more than 2 million students attended K-12 schools throughout the state, with 1,755,236 enrolled in public schools and 265,545 students in private schools (United States Department of Education, 2015). The Department of Education has composed state and grade-level standards for Science and Technology to measure appropriate learning for each student. The standards address what knowledge students should demonstrate by the end of fourth, seventh, tenth and twelfth grade and "aim to reflect the increasing complexity and sophistication that students are expected to achieve as they progress through school" (State Department of Education, 2012). Teachers are expected to exhibit high levels of capability to apply knowledge of content, processes and skills related to technology to provide students with diverse instruction. 


\section{The Digital Disparity in U.S. Public Schools}

Learning communities in urban, rural, and suburban settings are as unique and diversified as the neighborhoods they serve. A disparity of financial resources among school districts has led to a digital divide, defined as "the inequality and access to technology that exists between communities due to regional and demographic differences, particularly socioeconomic groups" (Tate \& Warschauer, 2017). Prior studies have indicated urban and rural schools confront a larger number of obstacles related to financial support, access to technology, quality of teaching, teacher supply, and classroom management than suburban schools (Kozol, 1991; Fishman \& Pinkard, 2001; Mouza \& Barrett-Greenly, 2015). Suburban schools have a greater chance of being located in more affluent communities with higher education levels. These school districts are typically better financed, appropriate more money per student, and serve a predominantly white population. As a result, these district administrators are more likely to provide financial support and appropriate training to faculty and staff (Leonardo \& Grubb, 2014).

Teachers in urban settings face various challenges related to educational technology. On average, these districts have larger student populations than those in suburban and rural settings. Also, they operate in a highly bureaucratic system that may hinder the integration and consistency of technology usage by teachers and students (Mouza \& Barrett-Greenly, 2015). Furthermore, usage of technology may be affected by teacher morale. Urban teachers have reported lower self-efficacy levels related to educational technology and less hours of administrative-led training (Herold, 2016). A disparity in teacher readiness to effectively utilize educational technology also exists. Minority teachers in urban schools are twice as likely to not have received adequate technology training, developed content specific skills, or acquired sufficient content area knowledge to design and employ technology within an educational framework (Yentes \& Gaskill, 2015). Prior research has suggested those teaching in suburban school districts are the most innovative with technology. By comparison, educators in urban schools are more likely to utilize technology in a rigid fashion, typically for drill and practice (Tate \& Warschauer, 2017).

In many cases, urban schools are located in low socioeconomic neighborhoods. A small, dwindling, or non-existent tax base may have a crippling effect on a district's technology budget for multiple academic years. Faced with rising costs and declining tax revenue, many urban schools lag behind their rural and suburban counterparts in money spent per student (Mouza \& Barrett-Greenly, 2015). Urban schools have a more diverse student population with a higher composition of minorities than other types of school districts. Although these schools have encountered a significant increase in Hispanic students during the last 20 years, these learning communities still remain mainly populated by African Americans. Like their urban counterparts, rural school districts are challenged by funding shortages and lack of technology integration.

High poverty rates in rural schools, like those in urban areas, have a negative impact on school budgets related to technology and teacher compensation. As a result, rural schools experience higher rates of teacher turnover and teacher shortages and spend less money on average per student than urban and suburban districts (Barrett et. al., 2015). Rural communities feature a higher percentage of English language learners, students with special needs, and a low ratio of college-bound students (Azano \& Stewart, 2015). Educational technologies may prove vital in the rural environment due to their ability to close language and learning gaps for ELL and disabled students (Song \& Samimy, 2015). Also, smaller enrollments of rural school districts can be an asset for both teachers and students. Teachers in these districts have indicated higher levels of freedom and greater amounts of preparation time. Previous research suggests relationships between teachers and students are commonly longer in nature and closer than those in suburban and urban schools (Hoffman et al., 2017). However, due to sometime remote locals, rural schools struggle with consistent and reliable Internet access. Inability to routinely access necessary bandwidth can limit teacher access to learning materials such as videos, images, documents, and assignments (Azano \& Stewart, 2015). 


\section{METHODOLOGY}

\section{Instrument}

This quantitative inquiry employed a researcher-designed questionnaire to explore a Mid-Atlantic state's K-12 public school teacher satisfaction with Internet speed and access, usage frequency of educational technologies and perceived effectiveness. A State Department of Education list of email addresses for each school principal provided respondents. Qualtrics, an Internet-based survey instrument system, served as the platform to create the survey and email each principal. Content of the message included an explanation of the purpose of study along with a request to forward the email to all faculty. A hyperlink to the informed consent and survey were included in the email. The questionnaire recorded responses for 28 days. The survey included three questions from prior research and instruments developed by Kotrlik and Redmann (2009) and Coley et al. (2015). The first section included eight questions to explore teacher satisfaction levels of access to technology and administrative training. The next segment contained 12 questions that pertained to usage frequencies and attitudes of effectiveness of software programs and applications. The final portion consisted of demographic questions including age, gender, years of full-time teaching experience, and grade levels and subjects taught.

Participants self-indicated if their school building was located in a suburban, urban, or rural location. For the purpose of this study, school setting definitions were adopted from the National Center for Education Statistics (2014). Urban schools were defined as within a city, a population comprised of at least $20 \%$ minority students, and a $20 \%$ minimum of students who received free or reduced lunch. Rural schools were operationally defined as located in a small town or rural area with less than 25,000 people. This study defined suburban schools as located in an urban fringe, but not in a rural area. Suburban schools feature less than $20 \%$ diversity related to student socioeconomic status and ethnicity.

\section{RESULTS}

\section{Participants}

The survey generated a total of 2,203 volunteer responses of K-12 teachers employed in a Mid-Atlantic State during the 2016-2017 academic year. For a confidence level of 95\%, a representative sample of 1,064 respondents was necessary (Creswell \& Creswell, 2017). A dropout rate of $10 \%$ left a total of 1,998 usable responses. The typical participant was 41 years old with 14 years of full-time teaching experience. Middle grades (grades 5-8) teachers represented the highest percentage of participants ( $N$ $=887 ; 44 \%)$, then grades $\mathrm{K}$ through $4(N=867 ; 43 \%)$, and $9-12(N=726 ; 36 \%)$. For future analysis, middle grades and secondary teachers identified subjects taught. English teachers $(N=342 ; 24 \%)$ had the highest number of responses, followed by math $(N=283 ; 20 \%)$, science $(N=256 ; 18 \%)$, special education $(N=224 ; 16 \%)$, and social studies $(N=199 ; 4 \%)$. Suburban $(N=898 ; 45 \%)$ and rural $(N=896 ; 45 \%)$ teachers were represented in almost equal numbers, followed by those in urban $(N=204 ; 10 \%)$ areas.

\section{OBJECTIVES}

The first objective explored a Mid-Atlantic state's K-12 public school teacher satisfaction with Internet access. A Levene's test of homogeneity $(F=4.258, p=.014)$ indicated unequal variances amongst the groups. Perception of Internet access was slightly significant based upon setting, Welch's $F(2,581.8)$ $=3.228, p=.040$ ). Further analysis with the Games-Howell multiple comparisons test did not reveal a significant effect at $\mathrm{p}<.05$ level between variables. Table 1 shows teacher satisfaction of school building Internet access $(M=3.94 ; S D=0.97)$. Rural teachers were most likely to either disagree 
Table 1. Comparison of teacher satisfaction with internet access

\begin{tabular}{|l|l|l|l|}
\hline & \multicolumn{1}{|c|}{$\boldsymbol{N}$} & \multicolumn{1}{c|}{$\boldsymbol{M}$} & \multicolumn{1}{c|}{ ND } \\
\hline Overall group & 1,966 & 3.94 & 0.97 \\
\hline Rural & 888 & 3.88 & 1.00 \\
\hline Suburban & 877 & 3.98 & .095 \\
\hline Urban & 201 & 4.03 & .891 \\
\hline
\end{tabular}

Note. $1=$ =strongly disagree, 2=disagree, $3=$ neutral, 4=agree, $5=$ =strongly agree

or strongly disagree $(N=147 ; 16 \%)$ they were satisfied with Internet access, lower than suburban $(N=94 ; 10 \%)$ and urban $(N=21 ; 10 \%)$ counterparts. Analyzed together, responses indicate teacher satisfaction with Internet access by school setting is of some consequence.

Objective two investigated setting and teacher satisfaction with school-building Internet speed. A one-way ANOVA uncovered school setting had no significant effect at the $\mathrm{p}<.05$ level $[F(2$, $1962)=.819, p=.441]$. Overall, teachers reported lower satisfaction levels with Internet speed $(M=3.77$; $S D=1.05)$ than Internet access. Urban teachers were most positive about Internet speeds and had a smaller deviation than suburban and rural peers (Table 2).

Table 2. Comparison of teacher satisfaction of school-building internet speed

\begin{tabular}{|l|l|l|l|}
\hline & \multicolumn{1}{|c|}{$\boldsymbol{N}$} & \multicolumn{1}{c|}{$\boldsymbol{M} \boldsymbol{D}$} \\
\hline Overall group & 1,965 & 3.77 & 1.05 \\
\hline Rural & 887 & 3.74 & 1.06 \\
\hline Suburban & 877 & 3.79 & 1.05 \\
\hline Urban & 201 & 3.84 & 0.99 \\
\hline
\end{tabular}

Note. 1 = strongly disagree, 2 = disagree, 3 = neutral, 4 = agree, 5 = strongly agree

The third objective explored social media (i.e. Facebook, Instagram) usage frequency as an educational tool. A one-way ANOVA found a significant effect between the variables at the $\mathrm{p}<.05$ level $[F,(2,1794)=3.366, p=.021]$. Post-hoc comparisons using the Tukey HSD test indicated the difference of means for rural teachers was significantly lower than suburban teachers. The findings indicated rural teachers use social media at a much lower rate (Table 3). A majority of respondents $(N=1,464 ; 81 \%)$ never use social media, while $118(6 \%)$ did so on at least a weekly basis.

Objective four explored differences in perceived effectiveness of social media as an educational technology. A one-way analysis of variance indicated a significant effect of school setting on teacher

Table 3. Comparison of teacher usage frequency of social media

\begin{tabular}{|l|l|l|l|}
\hline & \multicolumn{1}{|c|}{$\boldsymbol{N}$} & \multicolumn{1}{c|}{$\boldsymbol{M}$} & \multicolumn{1}{c|}{$\boldsymbol{N}$} \\
\hline Overall group & 1,797 & 1.50 & 1.22 \\
\hline Rural & 815 & 1.33 & 1.11 \\
\hline Suburban & 797 & 1.59 & 1.30 \\
\hline Urban & 185 & 1.52 & 1.27 \\
\hline
\end{tabular}

Note. 1 = never, 2 = a few times a year, 3 = a few times a semester, $4=$ monthly, $5=$ weekly, $6=$ daily 
attitude $[F(2,1,772)=3.563, p=.029)]$. Post-hoc comparisons using the Tukey HSD test revealed the difference of means for urban teachers was significantly lower than both rural and suburban. The findings suggest urban teachers have significantly lower perceptions of effectiveness of social media for educational use (Table 4$)$. Only $19 \%(N=344)$ of respondents perceived the technology as effective, while $42 \%(N=760)$ stated the technology was not at all effective.

Table 4. Comparison of teacher perceived effectiveness of social media

\begin{tabular}{|l|l|l|l|}
\hline & \multicolumn{1}{|c|}{$\boldsymbol{N}$} & \multicolumn{1}{c|}{$\boldsymbol{M}$} & \multicolumn{1}{c|}{ SD } \\
\hline Overall group & 1,775 & 2.26 & 1.29 \\
\hline Rural & 803 & 2.28 & 1.25 \\
\hline Suburban & 793 & 2.29 & 1.31 \\
\hline Urban & 179 & 2.02 & 1.30 \\
\hline
\end{tabular}

Note. 1 = not at all, 2 = slightly, $3=$ neutral, $4=$ moderately, $5=$ extremely

The fifth objective investigated how often teachers utilize class websites. A one-way ANOVA $[F(2,1794)=8.000, p<.001)]$ discovered significant variation associated with school setting. Post hoc comparisons, using the Tukey HSD procedure, found urban teachers used class websites at a significantly lower rate than suburban and rural teachers. Only $28 \%(N=52)$ used a website at least one time per week, lower than rural $(N=354 ; 45 \%)$ and suburban $(N=380 ; 43 \%)$ teachers. Table 5 demonstrates that suburban teachers are most likely to use a class website.

Table 5. Comparison of teacher usage frequency of class websites

\begin{tabular}{|l|l|l|l|}
\hline & \multicolumn{1}{|c|}{$\boldsymbol{N}$} & \multicolumn{1}{c|}{$\boldsymbol{M}$} & \multicolumn{1}{c|}{ SD } \\
\hline Overall group & 1,797 & 3.49 & 2.08 \\
\hline Rural & 813 & 3.44 & 2.08 \\
\hline Suburban & 798 & 3.67 & 2.06 \\
\hline Urban & 186 & 2.91 & 2.04 \\
\hline
\end{tabular}

Note. 1 = never, 2 = a few times a year, 3 = a few times a semester, $4=$ monthly, $5=$ weekly, $6=$ daily

For the sixth objective, responses of perceived effectiveness were analyzed. A Levene's test of homogeneity $(F=6.14, p=.002)$ indicated unequal variances amongst the groups. As such, a Welch's $F$ test was performed $[(F(2,489.3)=6.30, p<.002)]$. A Tukey HSD test indicated mean scores for urban teachers were significantly lower than those in the suburbs. Post hoc testing also yielded a significant difference between suburban and rural teachers. Analyzed together, these results suggest school setting impacts teacher attitude towards the effectiveness of class websites. Specifically, suburban teachers reported most positive attitude toward perceived effectiveness (Table 6).

Objective seven explored how often teachers utilized video sharing during instruction. As determined by a one-way ANOVA $[(F(2,1792)=.457, p=.634)]$, school setting was not a significant variable. Suburban teachers continued to report the highest frequency of use. The standard deviations suggest there is a wide usage gap, particularly in rural and urban schools (Table 7). Urban teachers ( $N$ $=85 ; 42 \%)$ were least likely to use video sharing, then rural teachers $(N=271 ; 30 \%)$ and suburban teachers $(N=242 ; 29 \%)$. 
Table 6. Comparison of teacher perceived effectiveness of class websites

\begin{tabular}{|l|l|l|l|}
\hline & \multicolumn{1}{|c|}{$\boldsymbol{N}$} & \multicolumn{1}{c|}{$\boldsymbol{M}$} & \multicolumn{1}{c|}{$\boldsymbol{N}$} \\
\hline Overall group & 1,795 & 3.72 & 1.26 \\
\hline Rural & 813 & 3.65 & 1.25 \\
\hline Suburban & 798 & 3.83 & 1.22 \\
\hline Urban & 204 & 3.52 & 1.40 \\
\hline
\end{tabular}

Note. 1 = not at all, 2 = slightly, 3 = neutral, 4 = moderately, 5 = extremely

Table 7. Comparison of teacher usage frequency of video sharing

\begin{tabular}{|l|l|l|l|}
\hline & \multicolumn{1}{|c|}{$\boldsymbol{N}$} & \multicolumn{1}{c|}{$\boldsymbol{M}$} & \multicolumn{1}{c|}{ SD } \\
\hline Overall group & 1,794 & 3.28 & 1.75 \\
\hline Rural & 813 & 3.30 & 1.76 \\
\hline Suburban & 795 & 3.28 & 1.73 \\
\hline Urban & 186 & 3.17 & 1.80 \\
\hline
\end{tabular}

Note. 1 = never, 2 = a few times a year, 3 = a few times a semester, 4 = monthly, $5=$ weekly, 6 = daily

The eighth objective examined school setting and teacher attitude related to video sharing platforms such as YouTube and PlayPosit. A one-way ANOVA revealed a statistically significant main effect $[F(2,1787)=12.553, p=.012]$. Post hoc comparisons using a Tukey test indicated urban teachers perceived video sharing to be significantly less effective than both rural and suburban educators. Urban teachers $(N=36 ; 18 \%)$ were most likely to not use the technology at all, while suburban $(N=286 ; 36 \%)$ teachers reported the highest levels of neutrality compared to just $14 \%$ ( $N$ $=114$ ) of urban teachers (Table 8).

Table 8. Comparison of teacher perceived effectiveness of video sharing

\begin{tabular}{|l|l|l|l|}
\hline & \multicolumn{1}{|c|}{$\boldsymbol{N}$} & \multicolumn{1}{c|}{$\boldsymbol{M}$} & \multicolumn{1}{c|}{ SD } \\
\hline Overall group & 1,790 & 3.41 & 1.35 \\
\hline Rural & 804 & 3.44 & 1.27 \\
\hline Suburban & 785 & 3.46 & 1.29 \\
\hline Urban & 201 & 3.11 & 1.35 \\
\hline
\end{tabular}

Note. 1=not at all, 2=slightly, 3=neutral, 4=moderately, 5=extremely

Objective nine measured school setting and usage frequency of summative assessment technologies (i.e. Google Forms, Socrative). A Levene's test of homogeneity $(F=14.858, p<.002)$ exposed uneven variances between groups. A Welch's $F$ test $[F(3,1792)=13.562, p<.001)]$ indicated a significant difference between each of the three groups. A post hoc comparison using Games-Howell procedure found suburban teachers reported higher frequency of use than rural and urban teachers (Table 9). The majority of urban $(N=108 ; 53 \%)$ teachers reported they never used summative assessment technologies compared to $42 \%(N=431)$ of suburban teachers. Suburban $(N$ $=170 ; 22 \%)$ teachers used technology to conduct summative assessments more than rural $(N=128$; $16 \%)$ and urban $(N=24 ; 12 \%)$. 
Table 9. Comparison of teacher usage frequency of summative assessment platforms

\begin{tabular}{|l|l|l|l|}
\hline & \multicolumn{1}{|c|}{$\boldsymbol{N}$} & \multicolumn{1}{c|}{$\boldsymbol{M}$} & \multicolumn{1}{c|}{ SD } \\
\hline Overall group & 1,795 & 2.59 & 1.48 \\
\hline Rural & 807 & 2.45 & 1.45 \\
\hline Suburban & 787 & 2.78 & 1.54 \\
\hline Urban & 201 & 2.13 & 1.39 \\
\hline
\end{tabular}

Note. 1 = never, 2 = a few times a year, 3 = a few times a semester, $4=$ monthly, $5=$ weekly, $6=$ daily

The tenth objective examined the effect of school setting on perceived effectiveness of online summative assessment platforms. Levene's test of homogeneity $(F=4.175, p=.016)$ indicated unequal variances between groups. A Welch's $F$ test $[F(2,479.286)=18.176, \mathrm{p}<.001)]$ uncovered a significant difference between groups. To further explore the data, a Games-Howell test was utilized. The results uncovered a statistically significant relationship amongst each group. Specifically, rural and urban teachers reported lower attitude levels than those in the suburbs (Table 10). More than half of suburban $(N=495 ; 63 \%)$ and rural $(N=436 ; 55 \%)$ teachers perceived summative assessments as moderately or extremely effective, as compared to a minority of urban teachers $(N=63 ; 31 \%)$.

Table 10. Comparison of teacher perceived effectiveness of summative assessment platforms

\begin{tabular}{|l|l|l|l|}
\hline & \multicolumn{1}{|c|}{$\boldsymbol{| c |} M$} & \multicolumn{1}{c|}{ MD } \\
\hline Overall group & 1,763 & 3.19 & 1.16 \\
\hline Rural & 798 & 3.14 & 1.16 \\
\hline Suburban & 787 & 3.37 & 1.11 \\
\hline Urban & 200 & 2.68 & 1.24 \\
\hline
\end{tabular}

Note. 1 = not at all, 2 = slightly, 3 = neutral, 4 = moderately, 5 = extremely

\section{DISCUSSION}

\section{Limitations}

Participants for this study were limited to K-12 public school teachers in one Mid-Atlantic state during the 2016-2017 academic year. A second limitation occurred when the researcher relied on an intermediary to deliver the email request because it was not possible to contact the participants directly. The researcher sent an email containing a hyperlink to school principals who were requested to forward the email to their faculty. A third limitation was a relatively low number of urban respondents, possibly because only 32 of the state's 501 school districts are designated as urban. Despite a disparity in responses, participants provided a glance into how they incorporate technology regardless of setting. A final limitation is that repetitional analysis of an identical sample may result in alpha slippage. Therefore, it may be possible the family-wise alpha scores have been reduced.

\section{Conclusion and Implications}

The findings suggest school setting creates a significant difference in the frequency of usage and teacher attitude related to online-based educational technologies. Urban teachers consistently indicated significantly lower usage rates compared to their suburban and rural counterparts. The same is also true for video sharing, summative assessment tools, social media, and class websites. Significant 
differences were also found between rural and suburban teachers. Although rural teachers reported higher mean scores than their urban peers on nearly all variables, they lag behind those in suburban environments. Finally, suburban teachers reported the smallest standard deviations on nearly each variable. Responses indicated suburban teachers utilized educational technology most frequently and believed in its positive benefits.

In general, respondents revealed satisfaction with school-building Internet access and speed. However, a slight statistically significant relationship was found between setting and Internet access. Urban teachers identified as most likely to disagree or strongly disagree they were satisfied with Internet access but were most satisfied with Internet speed. It is important for urban teachers to be able to take advantage of classroom time to incorporate educational technology. Students of color in urban environments are less likely to have computer access at home and face barriers such as slower Internet speed and outdated hardware. Student limitations at home directly impact a teacher's capability to differentiate instruction at with technology. Unequal access to technology outside of the school building increases the struggle for teachers to create and experiment with existing technologies. A lack of resources in the classroom and in a student's home serve to maintain the digital divide between school-age children based upon socioeconomic status.

Frequent use of social media as an educational tool was not common for respondents. In particular, it was revealed rural teachers were least likely to use social media. Despite highest frequency of usage, urban teachers had a significantly lower perception of effectiveness than their counterparts. Since these learning communities are most likely to be "smartphone-dependent", the incorporation of platforms such as Facebook and Instagram may be of great benefit and increase asynchronous communication. Social media tools provide students a digital sphere to communicate with teachers and classmates, enhance accountability and present a forum to express themselves as they may not in a physical classroom.

Teachers in a suburban setting were most likely to use class websites and perceive them to be effective. Urban teachers reported significantly lower frequency of usage and attitude levels, and those in a rural setting were significantly lower than suburban. Class websites promote student preparedness, teamwork, cross-cultural collaboration, and increased cognitive ability by providing a consistent location for class information, schedules, resources, and content from multiple sources. Class websites provide benefits for individual student and general classroom performance. Prepared learners are more likely to engage in group discussion, promote social learning, exemplify higher levels of dialogue, attain higher grade averages, and report greater levels of intrinsic motivation than those who felt unprepared.

The questionnaire revealed no difference in how frequently teachers use video sharing as part of instruction. Urban teachers perceived video sharing to be significantly less effective than rural and suburban educators. An explanation may be a lack of financial resources in urban school districts. Prior studies suggested schools located in relatively affluent surroundings are more likely to purchase auxiliary resources such as videos. However, video sharing may be of great benefit for rural and urban learning communities. These student populations feature higher percentages of students with learning disabilities and language difficulties who could benefit greatly from visual learning.

Suburban teachers reported significantly higher frequency of use and perceptions of effectiveness of summative assessment platforms. Additionally, rural teachers revealed significantly higher means than urban respondents. These technologies utilize a variety of formats to determine student understanding and demonstrate knowledge through interactive assessments. Implementation of platforms such as Google Forms or Docs allow teachers, particularly those in an urban setting, to facilitate a technology-driven, student-centered learning experience as opposed to drill and practice instruction. Educators in a suburban environment reported highest levels of perceived effectiveness and are most likely to seek out and employ technology in an innovative manner. The availability of add-ons in Google platforms is an example of how supplemental alternatives can enhance the learning environment and provide student exposure to various media. 
The observed results highlight the discrepancy in educational technology urban, rural, and suburban schools face. By recognizing and understanding this imbalance, school leaders may identify designated areas of improvement and plan future professional development. It is important to recognize educators in urban and rural settings are less likely to be trained in the use of technology compared to their suburban counterparts. To close this gap, it is essential pre-service and current teachers are provided opportunities to receive appropriate guidance and practice. For any learning community to thrive, teachers need an opportunity to familiarize themselves with current and emerging technologies, their capabilities, and integration strategies to accomplish research-based goals from district and school-building administrators.

While this study examined teacher usage and perceptions of technology effectiveness, the results offer a foundation for future investigation and practice. Since participants were limited to K-12 public school teachers in one state, further research may be performed in other states and U.S.-accredited international schools. Qualitative research such as volunteer interviews with teachers may provide further insight of personal expectations related to technology usage. Interviews with administrators may lead to more defined expectations of technology integrated into the curriculum. Future quantitative studies may further examine significant relationships uncovered in this study, including reasons teachers search for and use particular technologies.

\section{Moving Forward}

This research may be incorporated into the development and delivery of professional development workshops and personalized teacher support. Schools need to prioritize faculty training of technologies that are available within the school. In addition, schools should promote an administration-generated list of specific technologies teachers should learn and implement. Through consistent and meaningful professional development, peers and administrators may offer check-up meetings after a professional development seminar to identify learning gaps and strategize future sessions. Technology-specific training of faculty would allow teachers to avoid pressures of finding new technology, as well provide an opportunity for cross-curricular and multi-grade and subject level collaboration amongst faculty. 


\section{REFERENCES}

Azano, A. P., \& Stewart, T. T. (2015). Exploring place and practicing justice: Preparing pre-service teachers for success in rural schools. Journal of Research in Rural Education, 30(9), 1.

Barrett, N., Cowen, J., Toma, E., \& Troske, S. (2015). Working with what they have: Professional development as a reform strategy in rural schools. Journal of Research in Rural Education (Online), 30(10), 1.

Blau, I., \& Hameiri, M. (2010). Implementing technological change at schools: The impact of online communication with families on teacher interactions through learning management system. Interdisciplinary Journal of E-Learning \& Learning Objects, (6), 245-257.

Chai, C. S., \& Kong, S. C. (2017). Professional learning for 21st-century education. Journal of Computers in Education, 4(1), 1-4. doi:10.1007/s40692-016-0069-y

Chen, A. (2015, November 6). The ever-growing Ed-tech market. The Atlantic. Retrieved from https://www. theatlantic.com/education/archive/2015/11/quantifying-classroom-tech-market/414244/

Coley, M. D., Warner, W. J., Stair, K. S., Flowers, J. L., \& Croom, D. B. (2015). Technology usage of Tennessee agriculture teachers. Journal of Agricultural Education, 56(3), 35-51. doi:10.5032/jae.2015.03035

Creswell, J. W., \& Creswell, J. D. (2017). Research design: Qualitative, quantitative, and mixed methods approaches. Sage Publications.

Falloon, G., \& Khoo, E. (2014). Exploring young students' talk in iPad-supported collaborative learning environments. Computers \& Education, 77, 13-28. doi:10.1016/j.compedu.2014.04.008

Fishman, B. J., \& Pinkard, N. (2001). Bringing urban schools into the information age: Planning for technology vs. technology planning. Journal of Educational Computing Research, 25(1), 63-80. doi:10.2190/6HDY-88WM2QHX-QY3D

Herold, B. (2016, July 5). Teachers in high-poverty schools less confident in Ed-Tech skills. EdWeek Market Brief. Retrieved from https://marketbrief.edweek.org/marketplace-k-12/teachers-in-high-poverty-schools-lessconfident-in-ed-tech-skills-survey-finds/

Hoffman, J. A., Anderson-Butcher, D., Fuller, M., \& Bates, S. (2017). The school experiences of rural youths: A study in Appalachian Ohio. Children \& Schools, 39(3), 147-155. doi:10.1093/cs/cdx010

Januszewski, A., \& Molenda, M. (Eds.). (2013). Educational technology: A definition with commentary. Routledge. doi:10.4324/9780203054000

Karchmer-Klein, R., Mouza, C., Harlow Shinas, V., \& Park, S. (2017). Patterns in teachers' instructional design when integrating apps in middle school content-area teaching. Journal of Digital Learning in Teacher Education, 33(3), 91-102. doi:10.1080/21532974.2017.1305305

Kotrlik, J. W., \& Redmann, D. H. (2009). Analysis of teachers' adoption of technology for use in instruction in seven career and technical education programs. Career and Technical Education Research, 34(1), 47-77. doi:10.5328/CTER34.1.47

Kozol, J. (1991). Savage inequalities: children in America's schools. New York: Harper Perennial.

Kraft, M. A., Papay, J. P., Johnson, S. M., Charner-Laird, M., Ng, M., \& Reinhorn, S. (2015). Educating amid uncertainty: The organizational supports teachers need to serve students in high-poverty, urban schools. Educational Administration Quarterly, 51(5), 753-790. doi:10.1177/0013161X15607617

Leonardo, Z., \& Grubb, W. N. (2014). Education and racism: A primer on issues and dilemmas. New York: Routledge.

Littlejohn, S. W. (1996). Theories of human communication. New York: Wadsworth.

Mouza, C., \& Barrett-Greenly, T. (2015). Bridging the app gap: An examination of a professional development initiative on mobile learning in urban schools. Computers \& Education, 88, 1-14. doi:10.1016/j. compedu.2015.04.009 
National Center for Education Statistics. (2014). "Urban/Rural" classification of schools and local education agencies. Retrieved from: http://www.papartnerships.org/pdfs/methodology.pdf

Song, S. Y., \& Samimy, K. (2015). The beliefs of secondary content teachers of English language learners regarding language learning and teaching. International Journal of TESOL and Learning, 4(1), 3-19.

Spencer, K. (2017). The psychology of educational technology and instructional media. Routledge. doi:10.4324/9781315200835

State Department of Education. (2002). Academic Standards for Science and Technology. Retrieved from: http:// www.stateboard.education.pa.gov/Documents/Regulations\%20and\%20Statements/State\%20Academic\%20 Standards/ScienceandTechnologyStandards.pdf

State Department of Education. (2015). Pennsylvania K-12 Education Spending. PA Spending and Enrolment Trends. Retrieved from http://www.openpagov.org/education_revenue_and_expenses.asp

Tate, T., \& Warschauer, M. (2017). The Digital Divide in Language and Literacy Education. In Language, Education and Technology (pp. 45-56). Cham: Springer.

Tyner, K. (2014). Literacy in a digital world: Teaching and learning in the age of information. Routledge. doi:10.4324/9781410601971

United States Department of Education. (2010). Transforming American Education: Learning Powered by Technology. Retrieved from https://www.ed.gov/sites/default/files/netp2010.pdf

Van Lieshout, M., Egyedi, T., \& Bijker, W. (2018). Social Learning Technologies: The introduction of multimedia in education. Routledge. doi:10.4324/9781315204659

Yentes, J., \& Gaskill, M. (2015, March). Technology Use in Rural and Urban Schools: Challenges and Opportunities in the Midwest. In Society for Information Technology \& Teacher Education International Conference (pp. 1415-1423). Association for the Advancement of Computing in Education (AACE).

Erik Kormos is an Assistant Professor of Educational and Assistive technologies at Ashland University. At AU, he also coordinates the M.Ed. of Educational Technology. Prior to higher education, he served as a middle grades and young adult social studies teacher in Barranquilla, Colombia.

Liliana Julio teaches English as a Second Language at Universidad Simon Bolivar in Barranquilla, Colombia. Her primary research interest is the use of technology in the traditional and ESL classrooms. 